\title{
BMJ Open Metabolic syndrome, associated factors and optimal waist circumference cut points: findings from a cross-sectional community-based study in the elderly population in Asmara, Eritrea
}

Oliver Okoth Achila (D) , Mathewos Araya, ${ }^{1}$ Arsema Brhane Berhe, ${ }^{1}$ Niat Habteab Haile, ${ }^{2}$ Luwam Kahsai Tsige, ${ }^{2}$ Bethelihem Yemane Shifare, ${ }^{2}$ Tesfaalem Abel Bitew, ${ }^{3}$ Israel Eyob Berhe, ${ }^{3}$ Isayas Afewerki Abraham, ${ }^{4}$ Eyob Garoy Yohaness ${ }^{5}$

To cite: Achila 00 , Araya M, Berhe AB, et al. Metabolic syndrome, associated factors and optimal waist circumference cut points: findings from a cross-sectional community-based study in the elderly population in Asmara, Eritrea. BMJ Open 2022;12:e052296. doi:10.1136/ bmjopen-2021-052296

- Prepublication history for this paper is available online. To view these files, please visit the journal online (http://dx.doi org/10.1136/bmjopen-2021 052296).

Received 14 April 2021 Accepted 11 January 2022

Check for updates

(C) Author(s) (or their employer(s)) 2022. Re-use permitted under CC BY-NC. No commercial re-use. See rights and permissions. Published by BMJ.

For numbered affiliations see end of article.

Correspondence to Oliver Okoth Achila; oliverachila@gmail.com

\section{ABSTRACT}

Objective The aim of the study was to investigate the prevalence of metabolic syndrome (MetSyn), associated factors, and optimal waist circumference (WC) cut points in a subset of the elderly population in Asmara, Eritrea. Design A community-based cross-sectional study conducted between January and June 2018.

Setting Asmara, Eritrea.

Participants Demographic, clinical biochemistry and anthropometric information were collected from a total of 319 elderly participants of African lineage (54.5\% men vs $45.5 \%$ women).

Main outcome measures Lipid profiles, fasting plasma glucose (FPG), anthropometric data, clinical profiles and demographic characteristic of patients were described. MetSyn was defined according to the International Diabetes Federation harmonised criteria.

Results The median age (IQR) of study participants was 67 (IQR: 63-72 years)-men 68 (IQR: 64-74) years versus women 65 (IQR: $62-70$ ) years, $p=0.002$. The prevalence of MetSyn was 90 (28.4\%). Abnormal values in MetSyn components were as follows: systolic blood pressure/diastolic blood pressure $\geq 130 / 85 \mathrm{~mm} \mathrm{Hg}$ or use of hypertension medication 133 (41.7\%); overweight/ obesity, 55 (25.1\%); abdominal obesity 129 (40.4); lowdensity lipoproptein cholesterol (LDL-C) $>130 \mathrm{mg} / \mathrm{dL}, 139$ (43.6\%); total cholesterol >200 mg/dL, 152 (47.6\%); nonhigh-density lipoproptein cholesterol (HDL-C) $>130 \mathrm{mg} /$ dL, $220(69.0 \%)$ and FPG ( $\geq 100-125 \mathrm{mg} / \mathrm{dL}), 35$ (12.7\%) and $F P G>125.17$ (6.2\%). Multivariate logistic regression analysis indicated that sex (females) (adjusted OR (aOR) $4.69,95 \% \mathrm{Cl} 2.47$ to 8.92$)$; non-HDL-C (aOR $1.09,95 \% \mathrm{Cl}$ 1.05 to 1.14); LDL-C >130 mg/dL (aOR 2.63, 95\% Cl 1.09 to 6.37 ) and body mass index (aOR $1.20,95 \% \mathrm{Cl} 1.10$ to 1.32) were independently associated with the presence of MetSyn. Optimal cut points for WC in men yielded a value of $85.50 \mathrm{~cm}$, a sensitivity of $76.0 \%$, a specificity of $61.0 \%$ and an area under receiver operating characteristics curve (AUROC) value of $74.0,95 \% \mathrm{Cl}(65.7$ to 82.4$)$. For women, the WC at a cut point value of $80.50 \mathrm{~cm}$ yielded the highest Youden index (0.41) with a sensitivity of $80 \%$,
Strengths and limitations of this study

- A major strength of this study is its communitybased design and the fact that it is the first study of its kind in Eritrea.

- Unverifiable responses by respondents may be limiting.

- The findings are limited by the reliance on single time point measurements of specific risk indicators (fasting plasma glucose and lipid panel data).

- Interpretation of cross-sectional analyses is limited due to problems associated with dissection of directionality of associations and the inability of multivariate models to adjust for all confounding factors.

- The lack of comprehensive data on a wide array of socioeconomic cultural factors and information on lifestyle components like nutrition/diet and sedentarism/physical inactivity was limiting.

a specificity of $39 \%$, and an AUROC of $73.4,95 \% \mathrm{Cl}(64.8$ to 82.5$)$.

Conclusions The MetSyn is highly prevalent in a subset of apparently healthy elderly population in Asmara, Eritrea. The findings support opportunistic and/or programmatic screening for CVD risk in the elderly during outpatient visits.

\section{BACKGROUND}

International data indicate that atherosclerotic cardiovascular disease (ASCVD) is the leading cause of death worldwide. ${ }^{1}$ Reports indicate that between 1990 through 2013, cardiovascular disease (CVD) deaths and associated disability-adjusted life years (DALYs) accounted for $26 \%$ to $32 \%$ of all deaths globally. ${ }^{1}$ In absolute numbers, CVD was associated with an estimated 17.3 million deaths and led to 330 million (13\%) DALYs lost in 
2013. ${ }^{1}$ At present, CVD causes four to five times as many deaths in low and middle-income countries (LMICs) as in high-income countries. ${ }^{2} 3$ According to some reports, Sub-Saharan Africa (SSA) bears the highest burden of stroke globally (age-standardised stroke incidence rates of approximately 316 per 100 000; age-adjusted prevalence rates of 14 per 1000 population and 1 month and 3 years case fatality rates $40 \%$ and $84 \%$, respectively). ${ }^{4}$

The observed increase in death rates can partly be explained by the rapid epidemiologic transition, particularly in LMICs. ${ }^{134}$ The excess mortality and morbidity observed in LMICs can also be attributed to the high co-occurrence of disorders associated with acceleration of atherosclerosis. ${ }^{12}$ The term metabolic syndrome (MetSyn) has been used to describe this recognisable clustering of risk markers. ${ }^{5}$ Disparate permutations, combinations and thresholds of these risk factors are emphasised in the existing MetSyn definitional criteria. ${ }^{56}$ The independent haemodynamic and immunometabolic abnormalities underpinning MetSyn include central obesity (intraabdominal or visceral obesity) atherogenic dyslipidaemia (high triglyceride (TG) and/or low-high density lipoprotein cholesterol (HDL-C)), elevated blood pressure (BP) and dysglycemia. ${ }^{5}$ Additional associations consist of hypofibrinolysis state/or hypercoagulability, impaired renal function, low-grade chronic systemic inflammation, abnormal function of the vascular endothelium, insulin resistance (IR), polycystic ovary syndrome, among others. $^{6}$

Interestingly, the MetSyn concept remains problematic in some quarters ${ }^{7-9}$ owing to several unresolved matters including performance in comparison to established diagnostic algorithms like Framingham risk Score; a unifying pathophysiological mechanism, and whether the risk associated with MetSyn is additive or multiplicative. Despite these reservations, the best available evidence supports the idea that MetSyn is a major contributor to the modern-day epidemics of type 2 diabetes mellitus (T2DM) and is at the centre of a broad spectrum of ASCVD. ${ }^{10}$ For example, long-term population studies have demonstrated that the presence of MetSyn is associated with a 3 to 5 -fold elevation of T2DM risk. ${ }^{11-13}$ The condition is also associated with a multiplicative/ or approximately 2-fold to 3-fold risk of incident CVD events and all-cause mortality. ${ }^{13}$ Importantly, a prominent systematic review and meta-analysis of 87 studies, in which either the US National Cholesterol Education Program Adult Treatment Panel III (NCEP-ATP III) or the American Heart Association/National Heart, Lung, Blood Institute definition was employed demonstrated that MetSyn has excellent discriminatory capacity for the prediction of CVD, CVD mortality, myocardial infarction (MI), and stroke (ischaemic stroke and haemorrhagic stroke). ${ }^{10}$ These determinations engender an important message from the public health point of view, namely, that timely diagnosis and treatment of MetSyn within a population offer the opportunity to delay or prevent the onset of T2DM and reduce the risk of ASCVD-two major causes of premature death and an elevation in DALYs in populations across SSA. 1415

As previously described, recent regional trends towards increasing rates of MetSyn and/or related noncommunicable diseases (NCDs) have compounded CVD-related mortality and morbidity in SSA. Previously identified barriers to addressing MetSyn, or by extension, the NCDs burden in the region, include lack of awareness, underdiagnosis/under-recognition, undertreatment and a limited understanding of its epidemiology. ${ }^{16}$ In particular, the lack of reliable community-based data undermines the formulation of data-driven national strategies for prevention and management/treatment of MetSyn in the region. In Eritrea, for example, data on MetSyn or CVD risk factor burden are extremely hard to find. The critical lack of data on MetSyn should be viewed against the fact that past WHO fact sheets have noted that age-standardised mortality due to DM or CVDs in Eritrea is disproportionately high. ${ }^{17}$ Curiously, the country has one of the lowest prevalence of overweight/obesity in the world. ${ }^{18}$ An obvious question to be asked here is this: How can a country with one of the lowest prevalence of overweight/obesity in SSA (and possibly in the world) present with one of the highest frequencies of CVD-related mortality and morbidity in the region? Without extending the argument into the stereotypical healthcare system and/or patient-centred rationalisations; a plausible, although less obvious answer relates to the possibility that body mass index (BMI) and/or existing cut points may be inappropriate markers of CVD risk in this population. This proposition has one added attraction: it emphasises the importance of global risk assessment tools such as MetSyn, which incorporate markers of intra-abdominal adiposity in this population.

Therefore, we set out to accomplish several goals. First, to evaluate the prevalence of MetSyn using the International Diabetes Federation (IDF) harmonised criteria in the elderly population in Asmara, Eritrea. Information on the prevalence of MetSyn may provide a useful window on the health of the elderly populations in the setting. Indeed, the data of MetSyn were complemented with additional information on the prevalence of multiple disorders or CVD risk indicators, including pre-diabetes, hypertension, specific lipids or lipoprotein abnormalities (including abnormalities in specific lipid ratios) and other medical problems. Altogether, this information can also be useful in informing and guiding healthcare policy and in the development of professional guidelines or quality improvement programmes directed at optimising health outcomes in geriatrics. Second, studies investigating cut points of specific anthropometric measures for MetSyn risk are exceedingly rare or practically non-existent for some countries, including Eritrea. Therefore, we evaluated optimal cut points associated with the presence of at least two components of MetSyn (excluding waist circumference (WC)). 


\section{DESIGN AND METHODS}

\section{Study setting and study design}

This was a cross-sectional epidemiological study conducted, as per the Strengthening the Reporting of Observational Studies in Epidemiology guideline for cross-sectional studies; in the elderly population (age $\geq 60-85$ years) between January and June 2018) in Asmara, Eritrea. Asmara is the capital city of Eritrea and has a population of $\sim 500000$ residents. A stratified sampling procedure employing multiple data collection strategies was employed. To this end, anthropometric measurements and biological data were collected and interpreted using standardised protocols/guidelines. Furthermore, a questionnaire, translated from English to Tigrigna (a common local dialect) and incorporating queries on a range of variables was employed to collect relevant demographic and health status information.

\section{Sample size calculation, participant recruitment, and selection}

The study was specifically designed to produce results that are representative of the elderly civilian population in Asmara. Asmara, the capital city of Eritrea, is important because it has a large population of elderly citizens. It also sets the trend for the rest of the country. The single proportion formula was used to estimate sample size. In this computation, the prevalence of MetSyn was assumed to be $20 \%,{ }^{19}$ a margin of $5 \%, 95 \% \mathrm{CI}$ and a design effect value (Deff) of 1.3. Based on this calculation, a total of 319 participants were recruited for the study.

A stratified sampling design was used to recruit participants. Briefly, the city is divided into 13 subzones to facilitate administration-Mai-Temenay, Edaga-Hamus, Akria, Paradizo, Aba-Shawel, Arbaete-Asmara, MaekelKetema, Tsetserat, Tiravelo, Sembel, Godaef, Gejeret and Geza-banda. The residential estates within these subzones are well delineated and have relatively homogenous socioeconomic backgrounds. Based on previous experience, 13 estates were randomly selected using the lottery method. Elderly individuals residing or working within these estates were subsequently invited to participate in the study. Inclusion criteria included individual's $\geq 60-85$ years of age and Asmara city residents for at least 1 year. Exclusion criteria were based on several considerations: mental illness/dementia, persons not willing to grant consent and patients with diabetes mellitus (DM). Potential participants were subsequently invited to attend a makeshift examination centre at the Asmara College of Health Sciences (ACHS). All recruits were requested to complete a questionnaire, undergo various examinations, and provide a blood sample.

\section{Data collection, measurements, and definitions}

Demographic and health history

Data collection used a predesigned data collection form (The WHO STEPwise Approach to NCD Risk Factor Surveillance (STEPS) questionnaire. The following information was collected using this form: age in years, sex, level of education, employment, self-reported history of hypertension, or other comorbidities (coronary, heart failure, among others).

\section{Lifestyle/behavioural factors}

Lifestyle factors (exposure to tobacco products, excessive alcohol intake and physical inactivity) were scored as per Fiseha et al. $^{19}$

\section{Clinical biochemistry measurements}

As per established protocols (standardised posturesitting quietly for $15 \mathrm{~min}$ before venipuncture), $5 \mathrm{~mL}$ of blood was obtained from the median cubital vein, after more than 8 hours of fasting. All samples were processed within 4 hours. Triacylglycerol (TG), total cholesterol (TC) and high-density lipoprotein cholesterol (HDLC), fasting plasma glucose (FPG) were analysed, as per manufactures' instructional protocols, using Beckman Coulter: AU480 Chemistry System. Friedewald formula (LDL=non-HDL-C-TG/5 (mg/dL) was used to estimate low-density cholesterol (LDL-C) concentration (participants with TG level $>400 \mathrm{mg} / \mathrm{dL}$ were excluded in this analysis). In addition, the following equation was used to evaluate non-HDL-C=TC - HDL-C. Lipid ratios were also computed. America Diabetes Association cut points were used to evaluate abnormalities in lipid panel markers and DM. ${ }^{20}$ Pre-diabetes was defined as FPG between $110 \mathrm{mg} /$ $\mathrm{dL}$ and $124.9 \mathrm{mg} / \mathrm{dL}$. Importantly, all the biochemical tests were completed within 4 hours.

\section{Anthropometric measurement}

Height (Ht), weight, BMI, WC, hip circumference (HC) data were collected by trained research assistants. Weight and height were measured, as per established guidelines, using standardised instruments. WC was measured using measuring tape at the midpoint between the lower rib margin and the iliac crest, taken at the end of exhalation. $\mathrm{HC}$ was measured at the largest part of the buttocks. WC and $\mathrm{HC}$ were adjusted for height using a waist-to-height ratio $(\mathrm{WC} / \mathrm{Ht})(\mathrm{WHtR})$ or waist-to-hip ratio $(\mathrm{WC} / \mathrm{HC})$ (WHR). All these measurements were performed twice and the average of the two measurements was used in subsequent analysis. BMI (a simple weight-to-height ratio) categories were defined as per WHO guidelines $^{15}$ : BMI $\leq 18.5 \mathrm{~kg} / \mathrm{m}^{2}$ (underweight); $18.6-24.9 \mathrm{~kg} /$ $\mathrm{m}^{2}$ (normal weight); $25-29.9 \mathrm{~kg} / \mathrm{m}^{2}$ (overweight); $\geq 30-34.9 \mathrm{~kg} / \mathrm{m}^{2}$ (obese class I); $35-39.9 \mathrm{~kg} / \mathrm{m}^{2}$ (obese class II) and $\geq 40 \mathrm{~kg} / \mathrm{m}^{2}$ (morbid obesity). Abdominal obesity was defined in line with the IDF specification as a $\mathrm{WC}>94 \mathrm{~cm}$ (men) $/ 80 \mathrm{~cm}$ (women). ${ }^{4}$ Abnormal waist/hip ratio (WHR) was defined according to the WHO criteria ( $>0.90$ men, $>0.85$ women).

\section{$\mathrm{BP}$, hypertension (BP) status and prehypertension}

Arterial BP was recorded using a calibrated digital sphygmomanometer (MDF Lenus Digital Blood Pressure Monitor) and appropriately sized arm cuff on subjects after 5 min seated rest. Three systolic blood pressure (SBP) and diastolic blood pressure (DBP) measurements were taken at least $5 \mathrm{~min}$ apart and the average 
of the second and third readings were used in this analysis. Hypertension was defined as per the Joint National Committee on The Prevention, Detection, Evaluation and Treatment of Hypertension guidelines. Prehypertension/high-normal BP was defined as SBP/DBP in the high-normal range of 120-139 mm Hg/80-89 mm Hg. Furthermore, pre-existing diagnosis of hypertension was determined by participants responding affirmatively to the question, 'Have you ever been diagnosed with hypertension' and 'Because of your hypertension/high BP are you now taking prescribed medicine?'

\section{Determination of MetSyn (ICD-10CM codes: E88.81)}

We used the IDF harmonised criteria to diagnose MetSyn. ${ }^{4}$ Any three out of the following five cardiometabolic risk markers are required to establish a positive diagnosis of MetSyn: WC ( $\geq 94 / 80 \mathrm{~cm}$ (men and women); hyperglycaemic defined as current use of antidiabetic medication (insulin or oral agents) or increased FPG $\geq 100 \mathrm{mg}$ / $\mathrm{dL}(5.6 \mathrm{mmol} / \mathrm{L})$ (although strongly recommended, oral glucose tolerance test was not conducted in this study); $\mathrm{SBP} / \mathrm{DBP} \geq 130 / 85 \mathrm{~mm} \mathrm{Hg}$ or current antihypertensive medication; TG $\geq 150 \mathrm{mg} / \mathrm{dL}(1.7 \mathrm{mmol} / \mathrm{L})$ or anti-TG medication and Hypo-HDL-C $\leq 40 \mathrm{mg} / \mathrm{dL}(1.03 \mathrm{mmol} /$ $\mathrm{dL})$ in $\mathrm{men}$ and $\leq 50 \mathrm{mg} / \mathrm{dL}(1.29 \mathrm{mmol} / \mathrm{dL})$ in women.

\section{Data analysis}

Data analysis was conducted using IBM SPSS Statistics (SPSS, V.20.0, Chicago, Illinois) and GraphPad Prism V.6 (GraphPad Software, La Jolla, California). Frequency (percentages), the mean $\pm \mathrm{SD}$ and median $\pm \mathrm{IQR}$ were used to describe the variables as appropriate. All variables were assessed for Gaussian distribution using KolmogorovSmirnov test, Shapiro-Wilk test and visual inspection of normality plots. Levene test was used to evaluate homogeneity of variances. Additionally, the baseline characteristics of study participants were analysed using student's $t$ test or Mann-Whitney $U$ test and one way analysis of the variance (ANOVA) or non-parametric equivalents (Kruskal Wallis) (numerical variables). Fishers least significant difference (LSD) testing of multiple post hoc comparisons was used in conjunction with ANOVA. Furthermore, $\chi^{2}$ test/or the Fishers exact test (categorical variables) and linear-by-linear relationships were used to evaluate differences between categorical variables. Multivariable logistic regression (backward: conditional) models were subsequently fitted to identify factors associated with the presence of MetSyn. Variables with a $\mathrm{p}$ value $\leq 0.25$ were included in this analysis. Model fit and multicollinearity were assessed using and Hosmer and Lemeshow test and variance inflation factor. Separately, non-parametric area under receiver operating characteristics curve (AUROC) analyses were conducted to assess and compare the ability of specific anthropometric measures (BMI, WC, HC and WHtR) to predict the presence of any two components of MetSyn (excluding WC). Besides, plots of sensitivity (true positives (TPs)) vs one minus specificity (false positives (FPs) ) were subsequently constructed. The Youden Index was calculated using ( $\mathrm{J}=$ sensitivity $(\mathrm{S})+$ specificity $(\mathrm{SP})$ $1),{ }^{21}{ }^{22}$ by yielding the TP rate $(\mathrm{S})$ and $\mathrm{FP}$ rate (1-SP) when $\mathrm{J}>1$. In addition, positive (sensitivity/1-specificity) and negative (1-sensitivity/specificity) likelihood ratios were computed to aid in the identification of optimal cut points (Youden Index; likelihood ratios $>1$ indicate association with the disease, whereas ratios $<1$ indicate association with the absence of the disease). Two-sided $p$ values $<0.05$ were accepted as statistically significant. Missing values were handled by exclusion from analysis.

\section{Consent and permissions}

The research proposal, the questionnaire and the consent form were reviewed and approved by the Eritrean Ministry of Health Research Ethical Committee and ACHS Scientific and Ethical Committee. Informed consent was obtained from all participants after extensive explanation of the study objective and/or purpose and possible adverse effects. Participants were duly informed of their rights to refuse or terminate their participation in the study at any time. Information on the maintenance of data confidentiality and integrity was also provided. Strict adherence to approved laboratory protocols was observed during specimen collection.

\section{Patient and public involvement}

The study participants and the public were not involved in the questionnaire development. However, the participants were provided with their results. In addition, some patients were advised to see a doctor.

\section{RESULTS}

Clinical and demographic characteristics of study participants In total, 356 prospective participants were processed. Twenty were excluded due to previous diagnosis of DM and 15 potential participants failed to grant consent for blood withdrawal. Ultimately, a total of 319 participants were eligible, of these, $174(54.5 \%)$ men and 145 $(45.5 \%)$ women were included in the study. There was a significant difference between the sexes in terms of level of education $(\mathrm{p}<0.001)$, employment status, $(\mathrm{p}<0.001)$, alcohol consumption $(\mathrm{p}<0.001)$, DBP $(\mathrm{p}<0.044)$, BMI $(p<0.001)$, WHR $(p<0.001)$, LDL-C $(p=0.002), \quad$ TC $(\mathrm{p}<0.001)$, non-HDL-C $(\mathrm{p}<0.001)$ and FPG $(\mathrm{p}<0.001)$. However, no significant difference was observed between the sexes in terms of age, family history of DM, smoking, hypertension and SBP. A significant proportion of the study participants had abnormal values in several modifiable CVD risk factors we evaluated: hypertension, 70 (21.9\%); SBP >130 mm Hg, 114 (35.7\%); DBP $>85 \mathrm{~mm}$ $\mathrm{Hg}, 163$ (51.1\%); BMI $\geq 25 \mathrm{~kg} / \mathrm{m}^{2}, 55$ (17.3\%); abnormal WHR, 128 (40.1\%); LDL-C >130 mg/dL, 139 (43.6\%); TC $>200 \mathrm{mg} / \mathrm{dL}, 152$ (47.6\%); non-HDL-C $>130 \mathrm{mg} /$ dL, $220(69.0 \%)$. Furthermore, participants who had FPG-defined pre-diabetes (FPG $\geq 100-125 \mathrm{mg} / \mathrm{dL}$ ) were $88(27.6 \%)$ and $\mathrm{FPG} \geq 125$ were $14(4.4 \%)$. Remarkably, $66(34.2 \%), 46(95.8 \%)$ and $100(10 \%)$ of the study 


\begin{tabular}{|c|c|c|c|c|}
\hline Variables & Male n (\%) & Female (\%) & P-value $\left(\chi^{2}\right)$ & Total (\%) \\
\hline \multicolumn{5}{|l|}{ Age } \\
\hline 60-69 years & $97(50.5)$ & $95(49.5)$ & \multirow[t]{3}{*}{$0.060(5.64)$} & $192(60.2)$ \\
\hline $70-79$ years & $63(57.8)$ & $46(42.2)$ & & $109(34.2)$ \\
\hline$>80$ years & $14(77.8)$ & $4(22.2)$ & & $18(5.6)$ \\
\hline \multicolumn{5}{|l|}{ Education } \\
\hline Illiterate & $23(21.7)$ & $83(78.3)$ & \multirow[t]{4}{*}{$<0.001$ (76.32) } & $106(33.2)$ \\
\hline Primary & $106(67.1)$ & $52(32.9)$ & & $158(49.5)$ \\
\hline Secondary & 37 (84.1) & $7(15.9)$ & & $44(13.8)$ \\
\hline Tertiary & 8 (72.7) & $3(27.3)$ & & $11(3.4)$ \\
\hline \multicolumn{5}{|l|}{ Employment status } \\
\hline Unemployed & $2(1.68)$ & $117(98.3)$ & \multirow[t]{3}{*}{$<0.001(217.05)$} & $119(37.3)$ \\
\hline Office work & $24(75.0)$ & $8(25.0)$ & & $32(10.0)$ \\
\hline Manual work & $148(88.1)$ & $20(11.9)$ & & $168(52.7)$ \\
\hline Family history of DM (yes) & $16(55.2)$ & $13(44.8)$ & $0.547(1.21)$ & $29(9.1)$ \\
\hline Smoking (yes) & 7 (2.2) & $0(0.0)$ & $0.051(5.96)$ & $7(2.2)$ \\
\hline Alcohol consumption (yes) & $90(74.4)$ & $31(25.6)$ & $<0.001$ (38.3) & $121(37.9)$ \\
\hline Hypertension (yes) & $35(50.0)$ & $35(50.0)$ & $0.417(0.233)$ & 70 (21.9) \\
\hline $\mathrm{SBP}(>130 \mathrm{~mm} \mathrm{Hg})$ & $82(58.6)$ & $58(41.4)$ & $0.214(1.631)$ & $114(35.7)$ \\
\hline DBP (>85 mm Hg) & $98(60.1)$ & 65 (39.9) & $0.044(4.18)$ & $163(51.1)$ \\
\hline \multicolumn{5}{|l|}{$\mathrm{BMI}\left(\mathrm{Kg} / \mathrm{m}^{2}\right)$} \\
\hline$<18.5$ & $40(59.7)$ & $27(40.3)$ & \multirow[t]{4}{*}{$<0.001(16.49)$} & $67(21.1)$ \\
\hline $18.6-24.9$ & $117(59.7)$ & $79(40.3)$ & & $196(61.4)$ \\
\hline $25-29.9$ & $16(34.0)$ & $31(66.0)$ & & $47(14.8)$ \\
\hline$>30$ & $1(12.5)$ & 7 (87.5) & & $8(2.5)$ \\
\hline WHR (>0.90 men, $>0.85$ women) & $31(24.2)$ & $97(75.8)$ & $<0.001(79.30)$ & $128(40.1)$ \\
\hline LDL-C >130mg/dL & $62(44.6)$ & $77(55.4)$ & $0.002(9.82)$ & $139(43.6)$ \\
\hline $\mathrm{TC}>200 \mathrm{mg} / \mathrm{dL}$ & $67(44.1)$ & $85(55.9)$ & $<0.001(12.83)$ & $152(47.6)$ \\
\hline Non-HDL-C>130 mg/dL & $103(46.8)$ & $117(53.2)$ & $<0.001(17.07)$ & $220(69.0)$ \\
\hline \multicolumn{5}{|l|}{ Fasting plasma glucose } \\
\hline Normal <100 mg/dL & $134(61.8)$ & $83(38.2)$ & \multirow[t]{3}{*}{$<0.001$ (18.2) } & $217(68.0)$ \\
\hline IFG ( $\geq 100-125 \mathrm{mg})$ & $38(43.2)$ & $50(56.8)$ & & $88(27.6)$ \\
\hline $\mathrm{FPG}>125 \mathrm{mg} / \mathrm{dL}$ & $2(14.3)$ & $12(85.7)$ & & $14(4.4)$ \\
\hline
\end{tabular}

P values (two tailed): Frequencies of specific demographic and clinical variables between males and females and associated $\chi^{2} /$ Fishers exact test values.

BMI, body mass index; DBP, diastolic blood pressure; DM, diabetes mellitus; FPG, fasting plasma glucose; HDL, high-density lipoprotein; IFG, impaired fasting glucose; LDL, low-density lipoprotein; SBP, systolic blood pressure; TC, total cholesterol; TG, triglycerides; WC, waist circumference; WHR, waist to hip ratio.

participants in the respective normal weight, overweight and obese categories had abnormal WC. Additional information is presented in table 1.

Table 2 presents data on the relationship between a number of cardiometabolic risk factors and sex. Overall, the median $( \pm \mathrm{IQR})$ age of the study participants was 67 years (63.0-72.0 years) (men: 68.06 years (64-74 years) vs women: 65 years $(62.0-70.0$ years), $\mathrm{p}=0.002)$. The median (IQR) BMI value was $21.08 \mathrm{~kg} / \mathrm{m}^{2}\left(19.0-24.0 \mathrm{~kg} / \mathrm{m}^{2}\right)$. A significant deference was observed in the median BMI value between the sexes $\left(22.0 \mathrm{~kg} / \mathrm{m}^{2} \quad\left(19.3-25.24 \mathrm{~kg} / \mathrm{m}^{2}\right)\right.$ inwomen vs $20.6 \mathrm{~kg} / \mathrm{m} 2\left(18.78-22.5 \mathrm{~kg} / \mathrm{m}^{2}\right)$ in men, $\left.\mathrm{p}<0.001\right)$. A significant difference $(p<0.001)$ between men and women was observed in the following values: LDL-C $(131 \mathrm{mg} / \mathrm{dL}$ $(111.5-153.0 \mathrm{mg} / \mathrm{dL})$ in women vs $115.0 \mathrm{mg} / \mathrm{dL}(99.0$ $142.0) \mathrm{mg} / \mathrm{dL}$ in men) and non-HDL-C $(157.0 \mathrm{mg} / \mathrm{dL}$ $(134.5-185.5 \mathrm{mg} / \mathrm{dL})$ in women vs $115.0 \mathrm{mg} / \mathrm{dL}(99.0$ $142.0 \mathrm{mg} / \mathrm{dL}))$ in men). Mean SBP $( \pm \mathrm{SD})$ and values were significantly higher $(\mathrm{p}<0.044)$ in men $(133.1 \pm 25.2 \mathrm{~mm} \mathrm{Hg}$ and $46.99 \pm 18.9 \mathrm{~mm} \mathrm{Hg}$, respectively) compared with women 
Table 2 Mean $( \pm S D)$, median $( \pm \mid \mathrm{QR})$ values of specific demographic, clinical and anthropometric characteristic of the study participants stratified by sex $(\mathrm{N}=319)$

\begin{tabular}{|c|c|c|c|c|}
\hline Variables & Male (174) & Female (145) & P-value & Total \\
\hline \multicolumn{5}{|l|}{ Median \pm IQR } \\
\hline Age (years) & $68.06(64-74)$ & $65(62.0-70.0)$ & 0.002 & $67(63.0-72.0)$ \\
\hline $\mathrm{BMI}\left(\mathrm{Kg} / \mathrm{m}^{2}\right)$ & $20.6(18.78-22.5)$ & $22.0(19.3-25.24)$ & $<0.001$ & $21.08(19.0-24.0)$ \\
\hline WC $(\mathrm{cm})$ & $85.0(78.0-92.0)$ & $87.0(78.0-93.0)$ & 0.606 & $86.0(78.0-92.0)$ \\
\hline WHR & $1.01(0.97-1.03)$ & $0.99(0.97-1.03)$ & 0.589 & $1.01(0.97-1.03)$ \\
\hline WHtR & $0.50(0.46-0.54)$ & $0.54(0.49-0.58)$ & $<0.001$ & $0.52(0.48-0.56)$ \\
\hline $\mathrm{TG}(\mathrm{mg} / \mathrm{dL})$ & $112(85.0-144.0)$ & $119(94.0-119.0)$ & 0.039 & $115.0(88.0-159.0)$ \\
\hline LDL-C (mg/dL) & $115.0(99.0-142.0)$ & $131(111.5-153.0)$ & $<0.001$ & $124(104.0-147.0)$ \\
\hline Non-HDL-C (mg/dL) & $141.0(117.0-167.0)$ & $157.0(134.5-185.5)$ & $<0.001$ & $150.0(125.0-173.0)$ \\
\hline \multicolumn{5}{|l|}{ Mean \pm SD } \\
\hline $\mathrm{DBP}(\mathrm{mm} \mathrm{Hg})$ & $86( \pm 12.0)$ & $84.71( \pm 8.6)$ & 0.641 & $85.54( \pm 8.6)$ \\
\hline SBP $(\mathrm{mm} \mathrm{Hg})$ & $133.1( \pm 21.36)$ & $126.2( \pm 18.86)$ & 0.044 & $130.2( \pm 1.19)$ \\
\hline Pulse pressure (mm Hg) & $46.99( \pm 18.9)$ & $42.66( \pm 16.06)$ & 0.027 & $45.03( \pm 17.76)$ \\
\hline $\mathrm{TC}(\mathrm{mg} / \mathrm{dL})$ & $192( \pm 38.96)$ & $213( \pm 40.6)$ & $<0.001$ & $200.8( \pm 41)$ \\
\hline $\mathrm{HDL}-\mathrm{C}(\mathrm{mg} / \mathrm{dL})$ & $48.34( \pm 10.0)$ & $52.34( \pm 11.15)$ & $<0.001$ & $50.0( \pm 10.38)$ \\
\hline $\mathrm{FPG}(\mathrm{mg} / \mathrm{dL})$ & $90.9( \pm 13.8)$ & $99.59( \pm 18.5)$ & $<0.001$ & $93.26( \pm 15.3)$ \\
\hline TG/HDL-C & $2.69( \pm 1.49)$ & $2.76( \pm 1.51)$ & 0.220 & $2.72( \pm 1.49)$ \\
\hline TC/HDL-C & $4.05( \pm 0.87)$ & $4.18( \pm 0.94)$ & 0.713 & $4.1( \pm 0.91)$ \\
\hline LDL/HDL & $2.51( \pm 0.72)$ & $2.63( \pm 0.75)$ & 0.168 & $2.56( \pm 0.74)$ \\
\hline Non-HDL/HDL & $3.05( \pm 0.87)$ & $3.18( \pm 0.94)$ & 0.220 & $3.11( \pm 0.91)$ \\
\hline
\end{tabular}

$P$ values (two tailed): Students t test comparing the mean values between males and females of selected determinants of metabolic syndrome (MetSyn): DBP, TC, HDL-C; P values (two tailed) Mann Whitney U comparing medians between males and females for specific parameters. BMI, body mass index; DBP, diastolic blood pressure; FPG, fasting plasma glucose; HDL, high density lipoprotein; LDL, low density lipoprotein; SBP, systolic blood pressure; TC, total cholesterol; TG, triglycerides; WC, waist circumference; WHR, waist to hip ratio.

$(126.2 \pm 18.86 \mathrm{~mm} \mathrm{Hg}$ and $42.66 \pm 16.06 \mathrm{~mm} \mathrm{Hg})$. However, mean TC value was significantly lower $(\mathrm{p}<0.001)$ in men $(192.0 \pm 38.96 \mathrm{mg} / \mathrm{dL})$ compared with women (213mg/ dL; SD $40.6 \mathrm{mg} / \mathrm{dL}$ ). Higher values were also observed in women in the following parameter: HDL-C ( $48.34 \pm 10.0 \mathrm{mg} /$ $\mathrm{dL}$ in women vs $52.34 \pm 11.15 \mathrm{mg} / \mathrm{dL}$ in men, $\mathrm{p}<0.001)$ and FPG $(90.9 \pm 13.8 \mathrm{mg} / \mathrm{dL}$ in women vs $99.59 \pm 18.5 \mathrm{mg} / \mathrm{dL}$ in men, $\mathrm{p}<0.001)$.

\section{Frequency of MetSyn and specific components}

Data on the frequency of MetSyn and related components as defined by the IDF consensus criteria are presented in table 3 . In this analysis, significant differences between men and women were observed in the following values: Abdominal obesity (32 (24.8\%) in men vs $97(75.2 \%)$ in women, $\mathrm{p}<0.001)$; hyperglycaemic, $40(39.2 \%)$ in men vs $62(60.8 \%)$ in women,

Table 3 Prevalence of individual abnormalities of the metabolic syndrome as defined by Consensus Statement Criteria in the elderly population in Asmara, Eritrea $(\mathrm{N}=319)$

\begin{tabular}{|c|c|c|c|c|}
\hline MetSyn component & $\begin{array}{l}\text { Male } \\
\text { N (\%) }\end{array}$ & $\begin{array}{l}\text { Female } \\
\mathrm{N}(\%)\end{array}$ & $\begin{array}{l}\text { P-value } \\
\left(\chi^{2}\right)\end{array}$ & $\begin{array}{l}\text { Total } \\
\text { N (\%) }\end{array}$ \\
\hline Abnormal obesity (WC $\geq 80$ or $94 \mathrm{~cm}$ in women and men & $32(24.8)$ & $97(75.2)$ & $<0.001(77.2)$ & $129(40.4)$ \\
\hline Hyperglycaemic (FPG >100 mg/dL) & $40(39.2)$ & $62(60.8)$ & $<0.001(14.21)$ & $102(32.0)$ \\
\hline Low HDL ( $\leq 40$ men and $\leq 50 \mathrm{mg} / \mathrm{dL}$ women) & $35(36.1)$ & $62(63.9)$ & $<0.001(19.2)$ & $97(30.4)$ \\
\hline $\mathrm{TG} \geq 150 \mathrm{mg} / \mathrm{dL}$ & $47(54.7)$ & $39(45.3)$ & $4.02(0.057)$ & $86(27.0)$ \\
\hline $\mathrm{SBP} / \mathrm{DBP} \geq 130 / 85 \mathrm{mmHg}$ or Use of HTN medication & $67(50.4)$ & $66(49.6)$ & $0.212(1.6)$ & $133(41.7)$ \\
\hline Metabolic syndrome & $26(28.9)$ & $64(71.1)$ & $0.001(32.6)$ & $90(28.4)$ \\
\hline
\end{tabular}

DBP, diastolic blood pressure; HDL, high density lipoprotein; IFG, impaired fasting blood glucose; SBP, systolic blood pressure. 
Table 4 Number of metabolic syndrome (MetSyn) components between males and females according to the Consensus Statement Criteria among the elderly population in Asmara, Eritrea

\begin{tabular}{|c|c|c|c|c|}
\hline Number of MetSyn components & $\begin{array}{l}\text { Men } \\
\mathrm{N}=172)\end{array}$ & $\begin{array}{l}\text { Female } \\
N=145\end{array}$ & $\begin{array}{l}\text { P-value } \\
\left(\chi^{2}\right)\end{array}$ & $\begin{array}{l}\text { Total } \\
\mathrm{N}=317\end{array}$ \\
\hline Zero trait & $49(28.5)$ & $18(12.4)$ & $<0.001(54)$ & $67(21.1)$ \\
\hline Two traits & $31(18.0)$ & 39 (26.9) & & $70(22.1)$ \\
\hline Three traits & $20(11.6)$ & $35(24.1)$ & & $55(17.4)$ \\
\hline Five traits & $0(0.0)$ & $12(8.3)$ & & $12(3.8)$ \\
\hline
\end{tabular}

$\mathrm{p}<0.001)$ and low HDL-C $(35(36.1 \%)$ in men vs 62 $(63.9 \%)$ in women, $\mathrm{p}<0.001)$. In contrast, a similar relationship was not observed for $\mathrm{TG} \geq 150 \mathrm{mg} / \mathrm{dL}(47$ $(54.7 \%)$ in men vs $39(45.3 \%)$ in women, $\mathrm{p}>0.057)$ and SBP $\geq 130$ and/or DBP $85 \mathrm{~mm} \mathrm{Hg}$ or using medication to lower BP (67 (50.4\%) in men vs $66(49.6 \%)$ in women, $\mathrm{p}>0.212)$. In aggregate, the prevalence of MetSyn in this population was 90 (28.4\%).

\section{Relationship between number of MetSyn components and specific cardiometabolic risk factors}

Table 4 presents data on the frequency of specific MetSyn traits. The proportion of patients with 0 traits was 67 $(21.1 \%)$. Similarly, $90(28.4 \%)$ of the study participants had one trait; $70(22.1 \%)$ had two traits; $55(17.4 \%)$ had three traits; $23(7.3 \%)$ had four traits and $12(3.8 \%)$ had five traits.

\section{Relationship between number of MetSyn components and specific cardiometabolic risk factors}

A similar relationship was observed in TG/HDL, TC/ HDL and non-LDL/HDL ratio (figure 1). In an alternative analysis, we evaluated the relationship between the number of MetSyn components and several CVD risk markers. Accordingly, a positive dose-response gradient between the number of MetSyn components and mean values of BMI, FPG, non-HDL-C, LDL-C, TC, TG, SBP,

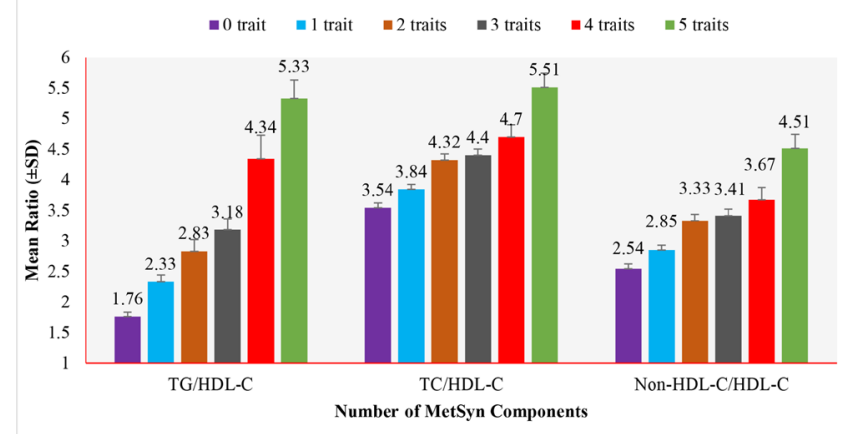

Figure 1 Relationship between the averages of lipids and lipoprotein ratios and number of MetSyn components. HDL-C, high-density lipoproptein cholesterol; MetSyn, metabolic syndrome; TC, total cholesterol; TG, triglyceride.
SBP, WHtR, WC and HC were noted. In contrast, a negative gradient was observed for HDL-C (table 5).

\section{AUROC and optimal cut points for specific anthropometric variables}

We examined the cut points for WC, BMI, HC and WHtR. Multiple risk factor aggregation (MRFA) was defined as the presence of two or more components of MetSyn, excluding WC. The AUROC for the prediction of the presence of $\geq 2$ components of MetSyn is presented in figure 2 . Among men, WC at a cut off value of $85.50 \mathrm{~cm}$ yielded the highest Youden index $(0.37)$ with a corresponding sensitivity of $76.0 \%$ and specificity of $61.0 \%$ (AUROC curve $74.0,95 \%$ CI (65.7 to 82.4)). At the recommended cut-off value of $94 \mathrm{~cm}$, the Youden index dropped to 0.25 , with a corresponding sensitivity of $36 \%$ and specificity of $89.0 \%$. For women, the WC at a cut point value of $80.50 \mathrm{~cm}$ yielded the highest Youden index $(0.41)$ with a sensitivity of $80 \%$ and specificity of $39 \%$ (AUROC 73.4, 95\% CI $(64.8$ to 82.5$)$ ). At the recommended cut point value of $80 \mathrm{~cm}$, the Youden index dropped to 0.31 with corresponding sensitivity and specificity of $52 \%$ and $89 \%$, respectively. Additional information on the other measures of obesity is presented in table 6 .

\section{Univariate and multivariate analysis of the risk factors associated with a diagnosis of MetSyn}

Table 7 presents the results of adjusted and unadjusted multivariate logistic regression analyses. Variables considered in the multivariable model included: sex, education, employment, TC, non-HDL-C, LDL-C, BMI and family history of DM. In the final model, five variables remained (sex, TC, non-HDL-C, LDL-C and BMI). Altogether, the analysis suggested that sex (females) (adjusted OR (aOR) $4.69,95 \%$ CI 2.47 to $8.92, \mathrm{p}<0.001$ ); non-HDL-C (aOR $1.09,95 \%$ CI 1.05 to $1.14, \mathrm{p}<0.001)$; LDL-C $>130 \mathrm{mg} / \mathrm{dL}$ (aOR 2.63, 95\% CI 1.09 to $6.37, \mathrm{p}<0.032$ ) and BMI (aOR $1.20,95 \%$ CI 1.10 to $1.32, \mathrm{p}<0.001$ ) were independently associated with the presence of MetSyn. In the bivariate analysis, a significant association $(p<0.05)$ was observed between MetSyn and the following variables: TC, sex; employment; non-HDL-C and BMI. A statistically borderline association between age grouping and MetSyn was also uncovered. 
Table 5 Relationship between number of MetSyn components and specific cardiometabolic risk factors

Number of MetSyn components

\begin{tabular}{lccccccc} 
Variables & Zero trait & One trait & Two traits & Three traits & Four traits & Five traits & P-value \\
\hline Mean and SD & & & & & & & \\
BMI $\left(\mathrm{Kg} / \mathrm{m}^{2}\right)$ & $18.9( \pm 2.1)$ & $20.4( \pm 2.8)$ & $22.7( \pm 8.9)$ & $24.5( \pm 3.4)$ & $25.1( \pm 4.0)$ & $25.0( \pm 1.1)$ & $<0.001^{*}$ \\
FPG $(\mathrm{mg} / \mathrm{dL})$ & $85.5( \pm 8.4)$ & $89.4( \pm 12.0)$ & $94.5( \pm 15)$ & $102.8( \pm 16)$ & $113.3( \pm 21)$ & $120.5( \pm 18)$ & $<0.001^{*}$ \\
Non-HDL-C $(\mathrm{mg} / \mathrm{dL})$ & $138.3( \pm 35)$ & $141.8( \pm 35)$ & $159.8( \pm 37)$ & $158.4( \pm 33)$ & $172( \pm 33.0)$ & $187( \pm 38.5)$ & $<0.001^{*}$ \\
LDL-C $(\mathrm{mg} / \mathrm{dL})$ & $119.5( \pm 32)$ & $119( \pm 33.0)$ & $133( \pm 34)$ & $129( \pm 30.0)$ & $132.6( \pm 32)$ & $143( \pm 39.0)$ & 0.011 \\
TC $(\mathrm{mg} / \mathrm{dL})$ & $194( \pm 39)$ & $193( \pm 42)$ & $209( \pm 41)$ & $206( \pm 36)$ & $220( \pm 36)$ & $228( \pm 42.0)$ & $0.001^{*}$ \\
TG mg/dL & $94.2( \pm 25.1)$ & $112.9( \pm 43)$ & $132.6( \pm 60)$ & $145( \pm 51.1)$ & $201( \pm 64.0)$ & $219( \pm 41.0)$ & $<0.001^{*}$ \\
HDL-C & $55.3( \pm 10)$ & $51.3( \pm 12.5)$ & $49.2( \pm 9.9)$ & $47.7( \pm 9.1)$ & $48.5( \pm 10.0)$ & $41.6( \pm 5.8)$ & $<0.001^{*}$ \\
SBP $(\mathrm{mm} \mathrm{Hg})$ & $120.2( \pm 17)$ & $130.7( \pm 19)$ & $130( \pm 21.5)$ & $140.4( \pm 24)$ & $141.5( \pm 24)$ & $136.8( \pm 17)$ & $<0.001^{*}$ \\
DBP $(\mathrm{mm} \mathrm{Hg})$ & $79.9( \pm 6.3)$ & $85.0( \pm 7.8)$ & $86( \pm 8.5)$ & $90.5( \pm 8.8)$ & $92.3( \pm 13.0)$ & $94.9( \pm 7.1)$ & $<0.001^{*}$ \\
Pulse pressure & $40.3( \pm 16.2)$ & $45.8( \pm 17.0)$ & $44.2( \pm 18.1)$ & $49.9( \pm 20.7)$ & $49.1( \pm 16.0)$ & $41.9(13.0)$ & $>0.053$ \\
WHtR & $0.47( \pm 0.03)$ & $0.50( \pm 0.06)$ & $0.53( \pm 0.1)$ & $0.58( \pm 0.07)$ & $0.58( \pm 0.05)$ & $0.58( \pm 0.06)$ & $<0.001^{*}$ \\
WC & $78.2( \pm 6.7)$ & $82.5( \pm 11.0)$ & $87.2( \pm 9.1)$ & $94.9( \pm 11.0)$ & $96.0( \pm 7.4)$ & $94.0( \pm 9.7)$ & $<0.001^{*}$ \\
HC & $78.3( \pm 8.3)$ & $82.5( \pm 11)$ & $88.5( \pm 9.3)$ & $96.1( \pm 11.5)$ & $98.1( \pm 9.1)$ & $96.2( \pm 13)$ & $<0.001^{*}$ \\
\hline
\end{tabular}

${ }^{*} \mathrm{P}$ value $<0.001$ for linearity test.

BMI, body mass Index; DBP, diastolic blood pressure; FPG, fasting plasma glucose; HC, hip circumference; HDL-C, high-density lipoproteins-cholesterol; LDL-C, low-density cholesterol; Non-HDL-C, non-high-density cholesterol; SBP, systolic blood pressure; TC, total cholesterol; WC, waist circumference; WHtR, waist to hip ratio.

\section{DISCUSSION}

A cardinal finding of the study is that $90(28.4 \%)$ of the screenees had MetSyn with a strong disparity between men and women (26 $(28.9 \%)$ vs $64(71.1 \%))$. Due, in part, to differences in definition criteria, published prevalence estimates of MetSyn vary broadly in SSA. Nevertheless, these findings compare favourably with multiple reports from the region. For instance, community-based studies applying the IDF harmonised criteria have reported a prevalence of $59(26 \%)$ in Ethiopia. ${ }^{23}$ A significantly higher prevalence was observed in women $42(35 \%)$ compared with men 17 (16\%). Data from other jurisdictions have also reported a prevalence of $12.5 \%(24.0 \%$ women vs $10.0 \%$, men) in Ethiopia ${ }^{24} ; 35.9 \%$ in Ghana $(55.8 \% \text { women vs } 15.7 \% \text { men })^{25}$ and in urban Kenya $34.1 \%{ }^{26}$ - note that a strong rural-urban gradient was reported in these studies. ${ }^{14}$ Alarmingly, the prevalence of MetSyn in this study was higher or nearly similar to the
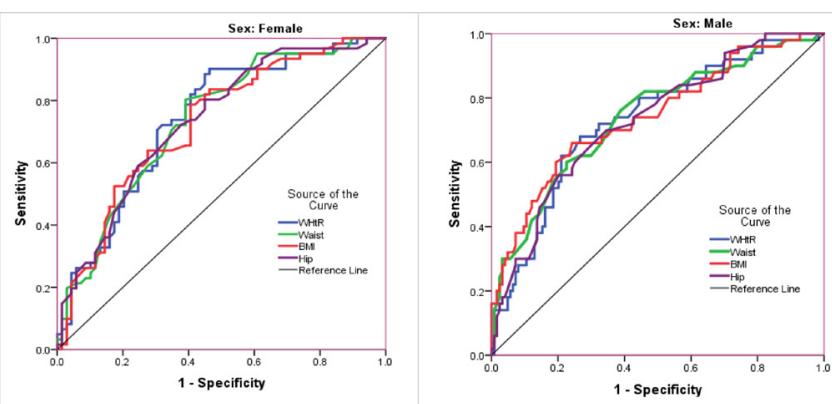

Figure 2 AUROC for specific anthropometric. AUROC, area under receiver operating characteristic curBMI, body mass index; WHtR, waist-to-height ratio. prevalence of MetSyn in some HIC and middle-income countries such as Canada (26\%), ${ }^{27}$ Turkey $(31.3 \%)^{28}$ and China $(27.3 \%){ }^{29}$

The elevated cardiometabolic risk in women is also supported by the higher proportion of women with abnormalities in multiple risk markers including elevated WHR, LDL $>130 \mathrm{mg} / \mathrm{dL}$; non-HDL-C $>130 \mathrm{mg} / \mathrm{dL}$ and $\mathrm{BMI} \geq 25 \mathrm{~kg} / \mathrm{m}^{2}$. In addition, women had higher averages/or median values in BMI, LDL-C, non-HDL-C, TC, HDL-C and FPG. These findings are not surprising given the fact that the percentage of all deaths secondary to CVD is higher among women (43\%) than among men $(37 \%)$. Indeed, reports indicate that MetSyn may play a more prominent role in the development of ASCVD in women than in men. Admittedly, the highlighted comparisons should be read with several caveats in mind. First, this study profiled individuals above 60 years of age while the age range in most studies is broader. ${ }^{142-26}$ Therefore, direct comparisons between our studies and other studies in the region may be misleading.

Multiple explanations have been invoked to explain the rapidly escalating epidemic of chronic lifestyle disorders like MetSyn in SSA. A stereotypical explanation invokes health transitions underpinned by the westernisation of lifestyles (rapid modernisation and urbanisation accompanied by rapid quantitative and qualitative changes in nutritional intake/obesogenic diet) and sedentarism. ${ }^{30}$ Lack of awareness; low access to quality prevention activities and care and a reactive healthcare model, which limits intervention at predisease states have also been implicated. ${ }^{3}$ Additional aetiologies include genetic predisposition; chronic stress; metabolic programming as 
Table 6 Results of the AUROC curve analyses for identifying optimal anthropometric cut-points for detecting more than two components of MetS (not including the WC in the analysis) ( $\mathrm{N}=319)$

\begin{tabular}{|c|c|c|c|c|c|}
\hline Variables & Cut-off & Sensitivity (\%) & Specificity (\%) & Youden index & AUC (95\% Cl) \\
\hline \multicolumn{6}{|l|}{ Overall } \\
\hline WC (cm) & 84.50 & 78.0 & 56.0 & 0.35 & 73.4 (67.7 to 79.2$)$ \\
\hline BMI $\left(\mathrm{Kg} / \mathrm{m}^{-2}\right)$ & 21.36 & 73.0 & 67.0 & 0.40 & 74.8 (69.1 to 80.5$)$ \\
\hline $\mathrm{HC}(\mathrm{cm})$ & 86.50 & 71.0 & 64.0 & 0.35 & 73.2 (67.4 to 78.9 ) \\
\hline WHtR & 0.51 & 82.0 & 63.0 & 0.45 & 75.4 (69.8 to 81.0$)$ \\
\hline \multicolumn{6}{|l|}{ Females } \\
\hline WC (cm) & 81.50 & 80.0 & 61.0 & 0.41 & 73.4 (64.8 to 82.4$)$ \\
\hline BMI $\left(\mathrm{Kg} / \mathrm{m}^{-2}\right)$ & 21.30 & 79.0 & 59.0 & 0.38 & 72.7 (64.0 to 81.3$)$ \\
\hline $\mathrm{HC}(\mathrm{cm})$ & 82.50 & 80.0 & 55.0 & 0.35 & 73.3 (64.8 to 81.9$)$ \\
\hline WHtR & 0.51 & 90.0 & 54.0 & 0.44 & 73.8 (65.3 to 82.4 ) \\
\hline \multicolumn{6}{|l|}{ Males } \\
\hline WC (cm) & 85.50 & 76.0 & 61.0 & 0.37 & 74.0 (65.7 to 82.4$)$ \\
\hline BMI $\left(\mathrm{Kg} / \mathrm{m}^{-2}\right)$ & 22.0 & 60.0 & 81.0 & 0.41 & 74.0 (65.6 to 82.5$)$ \\
\hline $\mathrm{HC}(\mathrm{cm})$ & 86.50 & 70.0 & 64.0 & 0.35 & 73.0 (64.8 to 81.1$)$ \\
\hline WHtR & 0.51 & 72.0 & 68.0 & 0.40 & 73.0 (64.7 to 81.3$)$ \\
\hline
\end{tabular}

AUROC, area under the receiver operating characteristic curve; BMI, body mass index; HC, hip circumference; WC, waist circumference; $\mathrm{WHtR}$, waist to height ratio.

a result of marginal undernutrition in utero and in early life; population growth and longevity. ${ }^{31}$ Emphasising the latter point, some investigators have averred that improved longevity and population growth are leading to increasing proportions and numbers of older people, with age-related diseases emerging as a significant trend in many parts of the world. ${ }^{32} 33$

Regardless, rapid transitions in social-cultural and economic structures and accompanying, nutrition and life styles imbalances do not seem to explain much in this setting. As a matter of fact, the J curve for BMI observed in many countries in the region was absent in this population. Furthermore, the low proportion of individuals with BMI $\geq 25 \mathrm{Kg} / \mathrm{m}^{2},{ }^{17}$ socioeconomic transition data, ${ }^{34}$ anecdotal and observational evidence appear to contradict the rapid-urbanisation and westernisation hypothesis. In contrast, the data showing that longevity has drastically increased in Eritrea in the last three decades (life expectancy at birth is 64.9 years up from 36 years in $1990^{34}$ ) suggest that ageing and sedentarism/physical inactivity may be the predominant drivers of cardiometabolic risk in this setting. This phenomenon is not unique to Eritrea. According to a WHO report on global health and ageing, the number of older people in LMICs/less developed countries is projected to grow by $250 \%$ between 2010 through 2050.

With respect to causality, multiple multiethnic studies have consistently noted that in some populations, MetSyn tends to rise monotonically and inexorably with advancing age, reaches a plateau and decreases in frequency as sarcopenia and reduced fat mass develop. ${ }^{35}$ In turn, ageing, with its concomitant changes in the vasculature, is associated with physical inactivity, increased weight, elevated BP/ hypertension, T2DM and other adverse cardiometabolic risk factors. ${ }^{3637}$ Although ageing is regarded as a CVD risk equivalent, we have to highlight the fact that long-term exposure to MetSyn (from childhood to adulthood) can accentuate the risk of high carotid intima medial thickness and T2DM in adulthood. ${ }^{37}$ The impact of ageing is substantiated by the Global Burden of Disease Study, which suggested that the absolute growth in numbers of people with T2DM in countries like India and China was partially explained by population growth and ageing. ${ }^{13}$

Based on the findings of a previous study, another plausible pathophysiological driver of MetSyn in this population is chronic stress. ${ }^{38}$ On the whole, stress-induced aberrant activation of neurohormonal systems such as the hypothalamus-pituitary-adrenal axis and an imbalance of the autonomic nervous system are associated with MetSyn. ${ }^{39}$ Unfortunately, studies on the connection between stress and prevalence of CVDs in jurisdictions within SSA are extremely rare. Beyond these explanations, we have to concede that the complex relationship between age and MetSyn is subjected to innumerable confounding and biasing factors and that a prominent role for other factors including patient and healthcare system factors including a reactive healthcare model is hard to refute.

The most predominant components of MetSyn abnormality among the study participants were elevated BP (SBP/DBP $\geq 130 / 85 \mathrm{~mm} \mathrm{Hg}$ or use of HTN medication) and abdominal obesity/intra-abdominal obesity. However, near equivalent proportion of the study participants presented with dysglycemia ( $F P G \geq 100 \mathrm{mg} / \mathrm{dL}$ ), low 
Table 7 Cross-tabulations, crude and adjusted ORs of factors associated with the presence of metabolic syndrome in urban the elderly populations in Asmara, Eritrea $(\mathrm{N}=319)$

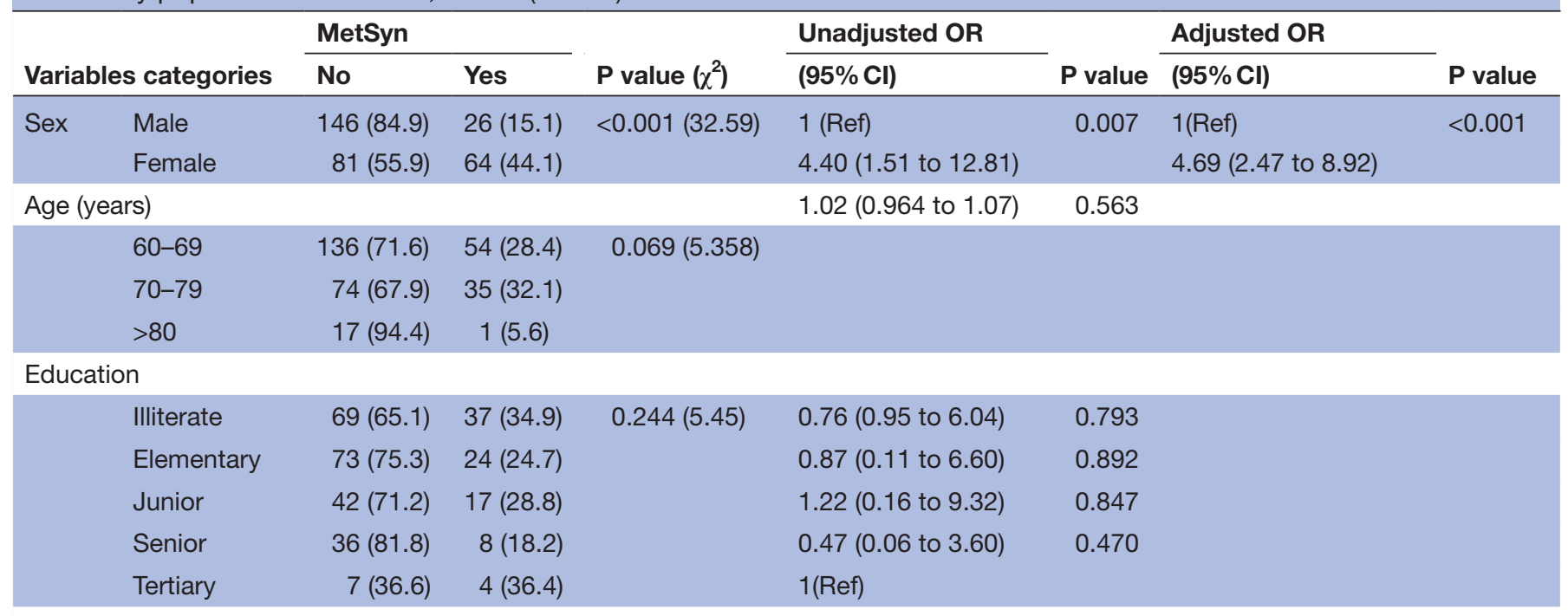

Employment

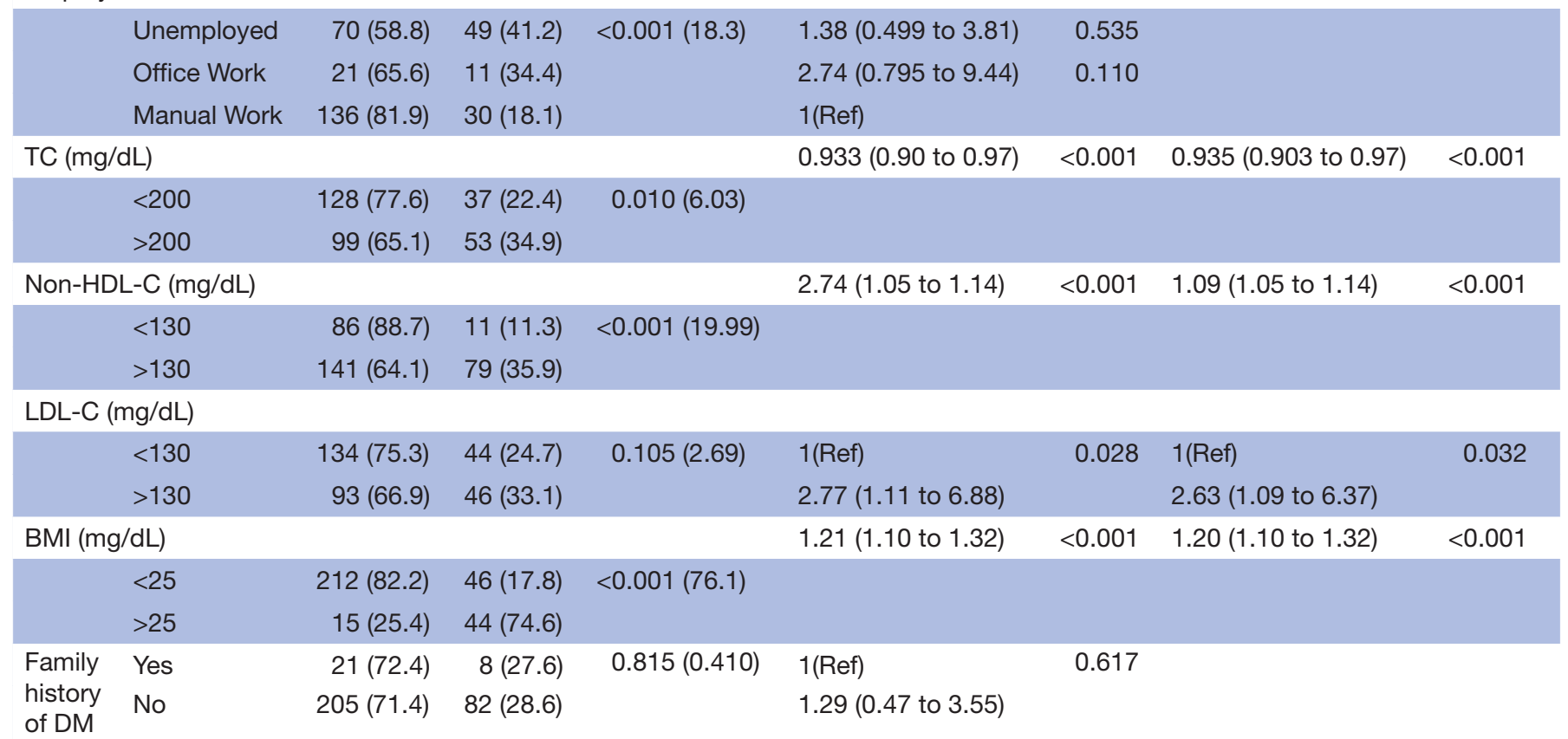

Variables with a p value $<0.25$ were included in the logistic regression analysis including sex, education level, employment status, age, TC (as continuous variable), non-HDL-C (continuous variable), LDL-C, BMI (continuous variables and family history of DM.

AUC, area under the curve; BAl, body adiposity index; BMI, body mass index; HC, hip circumference; HDL-C, high-density lipoproptein cholesterol; LDL-C, low-density lipoproptein cholesterol; TG, triacylglycerol; WC, waist circumference; WHR, waist to hip ratio; WHtR, waist to height ratio.

HDL-C and hypertriglyceridemia. These findings are, in general, concordant with results from previous reports ${ }^{1125}$ but can be distinguished from them in some aspects. For instance, the triad of high BP, central obesity and low HDL-C were responsible for MetSyn diagnosis in several jurisdictions. ${ }^{40-42}$ In contrast, heterogeneous patterning of risk factors has been reported in neighbouring countries like Ethiopia ${ }^{40}$ and Ghana. ${ }^{25}$ In view of the available evidence, the high proportion of patients with elevated BP should raise concern-note that approximately $62 \%$ of stroke and $49 \%$ of coronary heart disease cases are attributable to suboptimal (>115 mm Hg systolic) BP. $^{43}$

To identify the risk factors associated with MetSyn, we constructed stepwise multivariable logistic regression analysis. Analysis of associations using the CROSSTAB procedure was also undertaken. In this analysis, our study demonstrated that sex, employment status, TC, non-HDL-C, and BMI were associated with the presence of MetSyn. Although the level of education (a potential marker of socio-economic status) was not associated with 
MetSyn, manual workers were less likely to be diagnosed with MetSyn. This finding aligns closely with previous studies ${ }^{25}$ and corroborates our earlier assertion that sedentarism is a principal cause of MetSyn in this setting. In the adjusted multivariate analysis, sex, non-HDL-C, LDL-C, BMI were independently associated with the diagnosis of MetSyn. The association between MetSyn and a nontraditional marker of aberrant lipid metabolism like nonHDL-C is interesting for the simple reason that a strong association is known to exist between circulating nonHDL-C (encompasses all atherogenic lipoprotein particles VLDL, IDL, LDL, lipoprotein A) concentrations and elevated CVD risk. ${ }^{44} \mathrm{~A}$ strong correlation between nonHDL-C and ApoB and ApoC-III has also been reported. More importantly, NCEP ATP III identifies non-HDL-C as a secondary target of therapy in patients with TG between 200-499 mg/dL.

Another interesting finding was the relationship between the number of MetSyn traits and specific CVD risk markers. In this analysis, a positive dose-response gradient was observed between the number of MetSyn traits and higher averages in several variables - BMI, FPG, non-HDL-C, LDL-C, TC, TG, SBP, DBP, pulse pressure, WC, HC, TC/HDL-C, non-HDL-C/HDL-C, and TG/ HDL. The observed associations align with previous reports. ${ }^{45}$ The possibility that trait number correlates with incremental CVD risk was also reported in the highly influential Framingham Offspring Study. According to this report, females with one or two traits had a 6-fold higher risk of T2DM, and those with three or more traits had a 30 -fold higher risk. ${ }^{11}$ From another perspective, higher BP stages were associated with higher mean number of risk factors and higher rates of clinical CVD and/or target organ damage. ${ }^{46}$

Based on all these observations, the proposition that the number of MetSyn components is associated with increasing magnitude of specific CVD risk markers (TG/HDL-C, TC/HDL-C, and non-HDL-C) adds to the evidence on the utility of these markers and MetSyn in this setting. Note the fact that TG/HDL-C can act as a surrogate marker of the more atherogenic small dense LDL-C subfractions and a marker of IR. ${ }^{45}$ Equally important, ASCVD risk assessment tools such as the Systematic Coronary Risk Evaluation (SCORE) (10 year risk of CV death) use TC/HDL-C as an alternative input variable. However, we have to admit that without prospective studies from SSA on the clinical utility of lipid ratios in CVD risk assessment; drawing firm conclusions on the use of these markers can be premature.

Predictably, some reports have indicated that MetSyn phenotypes (component mix) are equally important and that components containing elevated $\mathrm{BP} /$ hypertension are consistently associated with incremental risk. ${ }^{47}$ Indeed, when hypertension coexists with overt T2DM, the risk for CVD and nephropathy is substantial. ${ }^{48}$ In addition, several lines of evidence suggest that the co-existence of elevated $\mathrm{BP}, \mathrm{IFG} /$ or dysglycaemia, and atherogenic dyslipidaemia in the elderly population are among the most serious presentation of MetSyn - by far, ASCVD is a major killer in patients with obesity and T2DM. Coming full circle, no rigorous outcome data are available to place into clinical context the relationship between the number of MetSyn traits and/or component mix (MetSyn phenotypes) and associated CVD risk in populations from SSA. Nonetheless, these finding provides information on an expanded list of indicators which can be used to develop alternative algorithms for screening

In a separate analysis, we evaluated the optimal cut points for specific anthropometric measures. This objective was largely driven by the conviction that optimal ethnic-specific cut points for markers such as WC can be useful as a screening tool that provides benefits in the detection of obesity and in the evaluation of risks of other NCDs such as T2DM and CVDs. ${ }^{49}$ More importantly, optimal deployment of IDF consensus criteria for MetSyn diagnosis presupposes the use of locally appropriate cut points. Finally, from a diagnostic point of view, surrogate markers of central adiposity like WC, HC, WHtR, among others, are cheap and easy-to-measure. Thus, they can have tremendous clinical and public health utility in LMICs or in resource poor countries. Another grossly under-recognised and under-characterised, but incredibly important concern, concerns the use of BMI in elderly populations. Data consistently indicate that age-related changes in height, sarcopenia/skeletal muscle atrophy, and increases in visceral adiposity make BMI a relatively inaccurate index in older subjects. ${ }^{50}$ The researchers in this study stated, unequivocally, that BMI has poor specificity in identifying older adults with obesity - missing obesity in over $50 \%$ of patients and even 3-fold in some SSA countries. ${ }^{350}$ The imperfections associated with BMI have prompted some experts to call for alternative ways to evaluate cardiometabolic risk in the elderly. ${ }^{51}$

Much of what is detailed in the foregoing paragraph aligns with the findings of this study. First, note the data showing that $34.2 \%$ of the study participants with normal BMI $\left(18.5 \leq \mathrm{BMI}<24.9 \mathrm{Kg} / \mathrm{m}^{2}\right)$ had elevated WC. This finding corroborates reports from a previous study which indicated that abdominal obesity is highly prevalent in a large number of individuals in the normal BMI range in SSA. ${ }^{3}$ Without a doubt, the high prevalence of abdominal obesity in overweight and normal-weight subjects can accentuate cardiometabolic disease. For instance, the EPIC-Inter Act case-cohort study reported that participants in the overweight $\left(\mathrm{BMI}=25-29.9 \mathrm{Kg} / \mathrm{m}^{2}\right)$ category and WC of $102 \mathrm{~cm}$ in men and $88 \mathrm{~cm}$ in women had a similar diabetes risk to obese individuals (BMI $30 \mathrm{~kg}$ / $\left.\mathrm{m}^{2}\right) .{ }^{52}$ They subsequently concluded that measuring WC in conjunction with BMI may allow clinicians to stratify risk for DM in overweight patients.

In a subsequent analysis, we demonstrated that a low BMI cut point (females 21.3 vs male $22.0 \mathrm{~kg} / \mathrm{m}^{-2}$ ) is required to maximise sensitivity and specificity. This suggests that CVDs may occur at a much lower BMI and that existing cut points for BMI may fail as a screening tool for metabolic disease in this setting. This finding dovetails 
well with previous reports which indicated that the risk of T2DM or MRFA can increase from a BMI $>22 \mathrm{~kg} / \mathrm{m}^{2}{ }^{53}$ Indeed, multiple studies have demonstrated that even patients with a normal BMI have increased CVD risk when WC is abnormal ${ }^{54}$ Further, our result also reconfirms the evidence from multiple reports on the need to investigate specific BMI cut points for identifying individuals at increased cardiometabolic risk in populations in SSA. ${ }^{31}$ While considering these aspects, it may be worthwhile to highlight the fact that clinics in Eritrea rely entirely on BMI as the sole index for weight management. This should raise concern.

In the last place, it is interesting to note that BMI, WC, HC and, WHtR had near similar AUROC values suggesting near similar performance at the population level. This observation has been confirmed repeatedly. For example, a previous meta-analytical and systematic review indicated that at the population level, BMI is highly correlated with $\mathrm{WC}$, and thus in epidemiological settings; they can give largely similar risk estimates for T2DM or other adverse endpoints. ${ }^{55}$ Unlike most studies in the region, ${ }^{56}$ our study appears to suggest that the difference in WC cut points between males and females is relatively narrow $(81.5 \mathrm{~cm}$ in female's vs 85.50 in male's). Remarkably, this result aligns partially with data from the African Partnership for Chronic Disease Research (APCDR) group which reported a similar WC cut point of $81.0 \mathrm{~cm}(95 \%$ CI 79.2 to $82.8 \mathrm{~cm}$ ) for males and females. ${ }^{31}$ It is uncertain if the observed disparities are entirely reflective of differences in population phenotypes or demographics. Despite this contrasting evidence, the two studies appear to suggest that the use of non-ethnic specific cut points such as the NCEP ATP III criteria (men/women $\leq 104 / 88 \mathrm{~cm}$ ) or IDF consensus guideline (men/women $\leq 94 / 80 \mathrm{~cm}$ ) may underestimate the prevalence of central obesity, hence, MetSyn in men in SSA. Fascinatingly, when we recalculated abdominal obesity for men based on the new the cut point; the prevalence of abdominal obesity in men increased twofold from $32(24.8 \%)$ to $63(51.1 \%)$. Finally, our data demonstrated that WHtR is strongly associated with CVD risk when compared with WC. In this regard, the study reinforces findings from multiple studies in the region. ${ }^{31}$

Although this study reported pertinent findings, it had a number of limitations. First, the participants were elderly individuals residing or working within specific residential estates in Asmara, Eritrea. Therefore, we have to admit that the sample was not fully randomised. Regardless, this mode of data acquisition is fairly representative. Indeed, the sociodemographic characteristics of the participants were broadly similar to what has been observed in the general population. Additional methodological drawbacks included unverifiable responses by respondents and reliance on single time point measurements for specific risk indicators (FPG or lipid and lipoprotein markers). Interpretation of crosssectional analyses is also limited due to problems associated with dissection of directionality of associations and the inability of multivariate models to adjust for all confounding factors.

\section{CONCLUSION}

These results represent the first attempt to present data on the prevalence of MetSyn and optimal cut point for specific anthropometric markers for any population in Eritrea. In this regard, the study provides novel datadriven insights into the risk burden of MetSyn and its relationship to specific modifiable risk factors. Without a doubt, the information/data on MetSyn could substantially contribute to explaining the very high rate of CVDrelated mortality and morbidity in patients both with and without clinical evidence of CVD in Asmara. Similar to other reports, the prevalence of MetSyn, hence CVD and/ or T2DM risk, was relatively high in this population, and women were disproportionately affected. Compared with men, women had higher median values in BMI, LDL-C and non-HDL-C. High mean values were also observed in the following parameters: TC, HDL-C and FPG. The most common MetSyn components included elevated BP, abdominal obesity, hyperglycaemic, low HDL-C and elevated TG. Furthermore, stepwise multivariate modelling demonstrated that the frequency of MetSyn was associated with sex (higher in females), elevated non-HDL-C, elevated LDL-C and elevated BMI. Most interesting was the demonstration that the number of MetSyn component is associated with higher averages in a number of traditional and non-traditional CVD risk markers. These observations call for concerted, highly committed multisectoral effort directed at scaling up early recognition and treatment, including optimal pharmacological and non-pharmacological therapy at all levels of care. Separately, analysis of optimal cut points indicated that the IDF recommended cut point of 80.5 for women may be appropriate for this population. In contrast, the recommended cut point for men $(94.0 \mathrm{~cm})$ may be inappropriate. Thus, the default cut point recommended in the harmonised IDF guideline may underestimate abdominal obesity, hence, MetSyn or CVD risk in men. This reinforces the need for prospective studies on populationspecific anthropometric cut points that can account for ethnic variation in adiposity and its association with CVD, T2DM and other metabolic comorbidities.

\section{Author affiliations}

${ }^{1}$ Allied Health, Orotta College of medicine and health sciences, Asmara, Eritrea ${ }^{2}$ Department of Clinical Laboratory Services, Asmara College of Health Sciences, Asmara, Central, Eritrea

${ }^{3}$ Department of clinical laboratory services, Asmara College of Health Sciences, Asmara, Central, Eritrea

${ }^{4}$ Department of Community Medicine and Health Sciences, Orotta College of Medicine and Health Sciences, Asmara, UK

${ }^{5}$ Allied Health, Orotta College of Medicine and health Sciences, Asmara, Eritrea

Acknowledgements The authors are grateful to the Eritrea Higher Education Council Sciences and Sembel Hospital for provision of material resources. The authors are also grateful for the technical assistance provided by the Sembel hospital stuff. 
Contributors MA, ABB, NHH, LKT, BYS, TAB, IEB, IAA, EGY conceived of the study, participated in the design, performed laboratory experiments. 00A, EGY performed the statistical analysis, participated in the design and reviewed/edited the manuscript. All authors read and approved the final manuscript.00A acts as a gaurantor of the study.

Funding The authors have not declared a specific grant for this research from any funding agency in the public, commercial or not-for-profit sectors.

Competing interests None declared.

Patient and public involvement Patients and/or the public were not involved in the design, or conduct, or reporting, or dissemination plans of this research.

Patient consent for publication Not applicable.

Ethics approval This study involves human participants and was approved by the research proposal, the questionnaire and the consent form were reviewed and approved by the Eritrean Ministry of Health (MOH) Research Ethical Committee and Asmara College of Health Sciences (ACHS) Scientific and Ethical Committee. These institutions do not provide ethics reference number of ID. Participants gave informed consent to participate in the study before taking part.

Provenance and peer review Not commissioned; externally peer reviewed.

Data availability statement Data are available upon reasonable request.

Open access This is an open access article distributed in accordance with the Creative Commons Attribution Non Commercial (CC BY-NC 4.0) license, which permits others to distribute, remix, adapt, build upon this work non-commercially, and license their derivative works on different terms, provided the original work is properly cited, appropriate credit is given, any changes made indicated, and the use is non-commercial. See: http://creativecommons.org/licenses/by-nc/4.0/.

\section{ORCID iD}

Oliver Okoth Achila http://orcid.org/0000-0001-8013-0785

\section{REFERENCES}

1 GBD 2013 Mortality and Causes of Death Collaborators. Global, regional, and national age-sex specific all-cause and causespecific mortality for 240 causes of death, 1990-2013: a systematic analysis for the global burden of disease study 2013. Lancet 2015;385:117-71.

2 Mensah GA, Roth GA, Sampson UKA, et al. Mortality from cardiovascular diseases in sub-Saharan Africa, 1990-2013: a systematic analysis of data from the global burden of disease study 2013. Cardiovasc J Afr 2015;26:S6-10.

3 World Health Organization African Regional Office. Cardiovascular diseases in the African region: current situation and perspectives, 2004. Available: http://www.afro.who.int/rc55/documents/afr_rc55_ 12_cardiovascular.pdf

4 Alberti KGMM, Eckel RH, Grundy SM, et al. Harmonizing the metabolic syndrome: a joint interim statement of the Internationa diabetes Federation Task force on epidemiology and prevention; National heart, lung, and blood Institute; American heart association; world heart Federation; international atherosclerosis Society; and international association for the study of obesity. Circulation 2009:120:1640-5.

5 Lorenzo C, Williams K, Hunt KJ, et al. The National Cholesterol Education Program - Adult Treatment Panel III, International Diabetes Federation, and World Health Organization definitions of the metabolic syndrome as predictors of incident cardiovascular disease and diabetes. Diabetes Care 2007;30:8-13.

6 Grundy SM, Cleeman JI, Daniels SR, et al. Diagnosis and management of the metabolic syndrome: an American heart Association/National heart, lung, and blood Institute scientific statement. Circulation 2005;112:2735-52.

7 Kahn R, Buse J, Ferrannini E, et al. The metabolic syndrome: time for a critical appraisal: joint statement from the American diabetes association and the European association for the study of diabetes. Diabetes Care 2005;28:2289-304.

8 Shin J-A, Lee J-H, Lim S-Y, et al. Metabolic syndrome as a predictor of type 2 diabetes, and its clinical interpretations and usefulness. J Diabetes Investig 2013;4:334-43.

9 Simmons RK, Alberti KGMM, Gale EAM, et al. The metabolic syndrome: useful concept or clinical tool? Report of a who expert consultation. Diabetologia 2010;53:600-5.

10 Clark LT, El-Atat F. Metabolic syndrome in African Americans: implications for preventing coronary heart disease. Clin Cardiol 2007;30:161-4.
11 Wilson PWF, D'Agostino RB, Parise H, et al. Metabolic syndrome as a precursor of cardiovascular disease and type 2 diabetes mellitus. Circulation 2005;112:3066-72.

12 Hwang Y-C, Jee J-H, Oh EY, et al. Metabolic syndrome as a predictor of cardiovascular diseases and type 2 diabetes in Koreans. Int $J$ Cardiol 2009;134:313-21.

13 Ford ES, Li C, Sattar N. Metabolic syndrome and incident diabetes: current state of the evidence. Diabetes Care 2008;31:1898-904.

14 van der Linden EL, Meeks K, Beune E, et al. The prevalence of metabolic syndrome among Ghanaian migrants and their homeland counterparts: the research on obesity and type 2 diabetes among African migrants (RODAM) study. Eur J Public Health 2019;29:906-13.

15 Narayan KMV, Ali MK, Koplan JP. Global noncommunicable diseases--where worlds meet. N Engl J Med 2010;363:1196-8.

16 Assah F, Mbanya JC. Diabetes in sub-Saharan Africa. In: DagogoJack S, ed. Diabetes mellitus in developing countries and underserved communities. Cham: Springer International Publishing, 2017: 33-48.

17 World Health Organization. Global health Observatory MAP gallery. Available: http://gamapserver.who.int/mapLibrary/app/searchResults. aspx

18 British Hearth Foundation Statistics website,. Prevalence estimates of overweight and obesity for 2002, and projections for 2005 and 2010, by sex, adults aged 15 and over, the world. from the surf report 2, surveillance of chronic risk factors: country-level data and comparable estimates. Geneva, Switzerland: WHO, 2005: 66-72, 73-79. https://apps.who.int/infobase/publicfiles/SuRF2.pdf

19 Fiseha T, Alemayehu E, Kassahun W, et al. Factors associated with glycemic control among diabetic adult out-patients in northeast Ethiopia. BMC Res Notes 2018;11:316.

20 American Diabetes Association. 2. classification and diagnosis of diabetes. Diabetes Care 2015;38:S8-16.

21 Youden WJ. Index for rating diagnostic tests. Cancer 1950;3:32-5.

22 Perkins NJ, Schisterman EF. The inconsistency of "optimal" cutpoints obtained using two criteria based on the receiver operating characteristic curve. Am J Epidemiol 2006;163:670-5.

23 Abda E, Hamza L, Tessema F, et al. Metabolic syndrome and associated factors among outpatients of Jimma university teaching hospital. Diabetes Metab Syndr Obes 2016;9:47-53.

24 Tran A, Gelaye B, Girma B, et al. Prevalence of metabolic syndrome among working adults in Ethiopia. Int $J$ Hypertens 2011;2011:193719.

25 Gyakobo M, Amoah AG, Martey-Marbell D-A, et al. Prevalence of the metabolic syndrome in a rural population in Ghana. BMC Endocr Disord 2012;12:25.

26 Kaduka LU, Kombe Y, Kenya E, et al. Prevalence of metabolic syndrome among an urban population in Kenya. Diabetes Care 2012;35:887-93.

2727 Liu J, Hanley AJG, Young TK, et al. Characteristics and prevalence of the metabolic syndrome among three ethnic groups in Canada. Int J Obes 2006;30:669-76.

28 Süleymanlar G, Utaș C, Arinsoy T, et al. A population-based survey of Chronic REnal Disease In Turkey--the CREDIT study. Nephrol Dial Transplant 2011;26:1862-71.

29 Lao XQ, Zhang YH, Wong MCS, et al. The prevalence of metabolic syndrome and cardiovascular risk factors in adults in southern China BMC Public Health 2012;12:64.

30 Mottillo S, Filion KB, Genest J, et al. The metabolic syndrome and cardiovascular risk a systematic review and meta-analysis. J Am Coll Cardiol 2010;56:1113-32.

31 Ekoru K, Murphy GAV, Young EH, et al. Deriving an optimal threshold of waist circumference for detecting cardiometabolic risk in subSaharan Africa. Int J Obes 2018;42:487-94.

32 Gaziano TA, Bitton A, Anand S, et al. Growing epidemic of coronary heart disease in low- and middle-income countries. Curr Probl Cardiol 2010;35:72-115.

33 Danaei G, Finucane MM, Lu Y, et al. National, regional, and global trends in fasting plasma glucose and diabetes prevalence since 1980: systematic analysis of health examination surveys and epidemiological studies with 370 country-years and 2.7 million participants. Lancet 2011;378:31-40.

34 United Nations Development Programme,. Statistical Annex, 2015. Available: http://hdr.undp.org/sites/default/files/hdr_2020_statistical_ annex.pdf

35 Kim TN, Choi KM. Sarcopenia: definition, epidemiology, and pathophysiology. J Bone Metab 2013;20:1-10.

36 Kelliny C, William J, Riesen W, et al. Metabolic syndrome according to different definitions in a rapidly developing country of the African region. Cardiovasc Diabetol 2008;7:27. 
37 Berenson GS, Srinivasan SR, Bao W. Association between multiple cardiovascular risk factors and the early development of atherosclerosis. Bogalusa heart study. N Engl J Med 1998;338:1650-6.

38 Mufunda J, Mebrahtu G, Usman A, et al. The prevalence of hypertension and its relationship with obesity: results from a national blood pressure survey in Eritrea. $J$ Hum Hypertens 2006;20:59-65.

39 Hall JE, do Carmo JM, da Silva AA, et al. Obesity-Induced hypertension: interaction of neurohumoral and renal mechanisms. Circ Res 2015;116:991-1006.

40 Solomon S, Mulugeta W. Disease burden and associated risk factors for metabolic syndrome among adults in Ethiopia. BMC Cardiovasc Disord 2019;19:236.

41 Davies Met al. Prevalent components of metabolic syndrome and their correlates in apparently healthy individuals in sub-Saharan Africa. Int J Trop Dis Health 2014;4:740-52.

42 Arthur FKN, Adu-Frimpong M, Osei-Yeboah J, et al. The prevalence of metabolic syndrome and its predominant components among preand postmenopausal Ghanaian women. BMC Res Notes 2013;6:446.

43 Institute for Health Metrics and Evaluation (IHME). GBD compare. Seattle: IHME, University of Washington, 2015.

44 Ridker PM, Rifai N, Cook NR, et al. Non-Hdl cholesterol, apolipoproteins $\mathrm{A}-\mathrm{I}$ and $\mathrm{B} 100$, standard lipid measures, lipid ratios, and CRP as risk factors for cardiovascular disease in women. JAMA 2005;294:326-33.

45 Gasevic D, Frohlich J, Mancini GJ, et al. Clinical usefulness of lipid ratios to identify men and women with metabolic syndrome: a crosssectional study. Lipids Health Dis 2014;13:159.

46 Lloyd-Jones DM, Evans JC, Larson MG, et al. Cross-classification of JNC VI blood pressure stages and risk groups in the Framingham heart study. Arch Intern Med 1999;159:2206-12.
47 Holewijn S, den Heijer M, Swinkels DW, et al. The metabolic syndrome and its traits as risk factors for subclinical atherosclerosis. $J$ Clin Endocrinol Metab 2009;94:2893-9.

$48 \mathrm{KDOQI}$. KDOQI clinical practice guidelines and clinical practice recommendations for diabetes and chronic kidney disease. Am J Kidney Dis 2007;49:S12-154.

49 Murphy GAV, Asiki G, Young EH, et al. Cardiometabolic risk in a rural Ugandan population. Diabetes Care 2013;36:e143.12.

50 Okorodudu DO, Jumean MF, Montori VM, et al. Diagnostic performance of body mass index to identify obesity as defined by body adiposity: a systematic review and meta-analysis. Int $J$ Obes 2010;34:791-9.

51 Ahima RS, Lazar MA, Physiology LMA. The health risk of ObesityBetter metrics imperative. Science 2013;341:856-8.

52 InterAct Consortium, Langenberg C, Sharp SJ, et al. Long-Term risk of incident type 2 diabetes and measures of overall and regional obesity: the EPIC-InterAct case-cohort study. PLoS Med 2012;9:e1001230.

53 Chiu M, Austin PC, Manuel DG, et al. Deriving ethnic-specific BMI cutoff points for assessing diabetes risk. Diabetes Care 2011;34:1741-8.

54 Sahakyan KR, Somers VK, Rodriguez-Escudero JP, et al. NormalWeight central obesity: implications for total and cardiovascular mortality. Ann Intern Med 2015;163:827-35.

55 Vazquez G, Duval S, Jacobs DR, et al. Comparison of body mass index, waist circumference, and Waist/Hip ratio in predicting incident diabetes: a meta-analysis. Epidemiol Rev 2007;29:115-28.

56 Owolabi EO, Ter Goon D, Adeniyi OV, et al. Optimal waist circumference cut-off points for predicting metabolic syndrome among low-income black South African adults. BMC Res Notes 2018;11:22 